\title{
Uma vida entre História, memória e arquivo: entrevista com Silvana Goulart
}

Entrevista por Marina de Almeida Spinola, Matheus de Paula Silva e Pedro José de Carvalho Neto

Transcrição por Marina de Almeida Spinola e Matheus de Paula Silva

Revisão por Beatriz Gasques Favilla, Guilherme Oliveira Souza e Matheus de Paula Silva

DOI: 10.11606/issn.2318-8855.v9i2p108-129 


\section{entrevista}

Uma vida entre História, memória e arquivo

Com seu forte - e belo - sotaque mineiro, Silvana Goulart nunca se sentiu uma exilada em São Paulo, cidade em que vive desde 1974. Apesar do ambiente hostil e burocratizado da USP, concluiu aqui o curso de História iniciado na Universidade Federal de Minas Gerais. Se a escolha da História havia sido uma vocação, ela encontrou na Arquivologia sua paixão, nos anos seguintes à diplomação.

Nessa entrevista instigante, Silvana nos conta sobre suas primeiras incursões nos arquivos, ainda nas disciplinas da graduação, seu estágio no Arquivo do Estado e sua atuação na empresa pioneira na área de memória institucional e produção cultural, a Grifo Projetos Históricos e Editoriais. Como a leitora e leitor poderá notar, as facetas da historiadora, documentalista e empresária se completam para lidar com o intricado e complexo campo da gestão de projetos culturais no Brasil. Aos interessados nessas áreas, Silvana recomenda a especialização e a procura por bons parceiros, mas sem esquecer que a História pode ser o ponto de partida e chegada.

Boa leitura a todas e a todos!

Revista Epígrafe: Nós gostaríamos de começar falando um pouco sobre seu percurso. Por que você quis fazer História? Por que você quis entrar para a área das Ciências Humanas e por que especificamente a História?

Silvana Goulart: As Ciências Humanas sempre foram uma vocação. Eu tive professores excelentes de História e descobri com a ajuda deles que tudo se relaciona com tudo, ou seja, a História pode ser um ponto de partida para as Ciências Humanas. Comecei a estudar na Universidade Federal de Minas Gerais; depois me mudei para São Paulo e aí tive a oportunidade de mudar de curso, mas persisti na História, na Universidade de São Paulo. Havia uma semelhança estrutural dos cursos da UFMG [Universidade Federal de Minas Gerais] e da USP, mas muita diferença 


\section{entrevista|}

Silvana Goulart

quanto ao formalismo no contato com os professores e na relação mais concorrencial entre os estudantes aqui em São Paulo. Mas enfim, sobrevivi e me formei.

Revista Epígrafe: Isso em que ano?

Silvana Goulart: Comecei na USP em 1974 e me formei no ano seguinte.

Revista Epígrafe: Você poderia falar um pouco sobre essa diferença entre Minas e São Paulo e como que você descreveria essa vida durante a graduação?

Silvana Goulart: O curso de História da UFMG era muito bom, aliás, feito à imagem e semelhança do curso da FFLCH da USP; a única diferença na grade é que em Minas não havia a disciplina História Ibérica Medieval. Mas lá havia grande proximidade entre os colegas, um espírito de turma, quase uma continuação do curso médio. $\mathrm{Na}$ USP eu achei tudo mais formal, competitivo e fiquei meio assustada, mas fiz alguns amigos. Além disso, me deparei com uma burocracia intrincada, quase hostil, e tive muita dificuldade na validação dos dois anos que havia feito na UFMG, o que é estranho, já que, como disse, eram cursos extremamente parecidos.

Mas a minha mudança para São Paulo nunca representou um exílio, eu gosto muito daqui e fiquei bem. Me formei e fui fazer um curso na França sobre o federalismo europeu, pois na época queria pesquisar o nosso federalismo. Ganhei uma bolsa do Instituto Europeu de Altos Estudos Internacionais, ligado à Universidade de Nice, em 1977 e 1978. Era um ciclo de estudos superiores das Comunidades Europeias, que à época buscava se institucionalizar. Com colegas da Europa, África e América - eu era a única sul-americana -, estudamos aspectos históricos, antropológicos, geográficos, econômicos e jurídicos ligados à formação da futura 


\section{entrevista|}

Uma vida entre História, memória e arquivo

Comunidade Europeia. Com as diferentes abordagens do curso, terminei de compreender como as várias facetas do conhecimento se relacionam e interpenetram e isso foi muito importante para mim.

Quando voltei para São Paulo, comecei a trabalhar no Arquivo do Estado, que na época era dirigido pelo Dr. José Sebastião Witter, professor de História do Brasil República no Departamento de História. Ele foi meu orientador no mestrado apresentei uma dissertação sobre o Departamento Estadual de Imprensa e Propaganda de São Paulo, o DEIP, discutindo a censura à imprensa e a propaganda política no Estado Novo de Getúlio Vargas. Esse trabalho foi editado mais tarde pela Rocco em livro intitulado Sob a verdade oficial, em coleção sobre a República brasileira.

No Arquivo do Estado, fui contratada como historiógrafa, em um bom momento no qual a instituição, por meio de um convênio com a Imprensa Oficial do Estado de São Paulo (Imesp), contratou seis historiógrafos e vinte estagiários, um luxo oriental para uma divisão da Secretaria da Cultura que vivia na penúria de recursos. Entrou uma moçada universitária, doida para fazer coisas. E o Arquivo naquela época era um lugar bem pequeno, instalado em uma antiga fábrica de tapetes, na rua Dona Antônia de Queiroz, uma travessa da rua Augusta, no centro da cidade. Era um ótimo lugar para trabalhar, muito simpático - inclusive, na quarta-feira, tinha feira ali perto e os funcionários almoçavam por lá, o que criava um clima muito aconchegante. Comecei a lidar com documentação histórica e esse vírus de arquivo me pegou. Me chocou a modéstia de condições da instituição frente à importância da missão de custodiar os arquivos públicos do Governo do estado e acho que isso acabou por criar em mim um compromisso próximo à militância, para defender algo que considero extremamente importante para a sociedade. Comecei a trabalhar com um conjunto de documentação cartorial, depositado em comodato, onde havia registro 


\section{entrevista|}

Silvana Goulart

de imóveis e civil, ou seja, um manancial de informações probatórias para a sociedade e de testemunho histórico. Depois fui organizar o arquivo pessoal de Júlio Prestes, político paulista que ganhou a eleição em 1930, mas não assumiu a presidência, em função da Revolução liderada por Getúlio Vargas. Ele, um representante da política do café com leite, ficou arrasado, desistiu da política e enterrou seus papéis em um silo de café de sua fazenda. Além de político e cafeicultor, ele era advogado - um político nos moldes da República Velha, apoiado por Washington Luís. Depois de anos de sua morte um sobrinho neto desenterrou esse arquivo e mandou para o Arquivo do Estado. Então passei a trabalhar nele e aí pronto, foi a paixão definitiva pelos papéis pessoais, esses em particular, com fungos, lacunas e umidade. Ficamos, uma pequena equipe, tempos de juntar as partes, limpar e aí passamos a receber a orientação de Heloísa Bellotto, historiadora, bibliotecária e já mergulhada na arquivologia.

Nesse momento, o Arquivo do Estado estava em uma fase dinâmica, de aprendizado, e como não havia o curso de arquivologia em São Paulo, a instituição promoveu seminários e aulas com arquivistas do Arquivo Nacional, da Fundação Getúlio Vargas, do Arquivo da Cidade do Rio de Janeiro. Também vieram profissionais europeus, norte-americanos e canadenses de alto nível, professores da École de Chartes de Paris, grandes teóricos. Foram feitos seminários, jornadas, consultorias e tivemos a oportunidade de receber uma formação. A Ana Maria Camargo também estava no Arquivo do Estado nesse momento, coordenando trabalhos, discutindo e o grupo formado nessas circunstâncias, permaneceu na área depois da formação e da prática vivida na instituição. A organização do acervo de Júlio Prestes de Albuquerque acabou por gerar um Inventário, publicado pelo Arquivo. 


\section{entrevista}

Uma vida entre História, memória e arquivo

Revista Epígrafe: E foi nesse período que você fez o seu mestrado? No período que estava trabalhando no Arquivo do Estado? Porque você trabalhou o período Vargas e a censura no seu mestrado...

Silvana Goulart: Eu achei no Arquivo do Estado uma documentação sobre o DEIP, o Departamento Estadual de Imprensa e Propaganda de São Paulo, dirigido por intelectuais paulistas, e me interessei pelo tema. Eu não pleiteei bolsa porque tinha medo de me afastar do mercado de trabalho e, naquela época, era longo o período de mestrado, as pessoas ficavam cinco, seis anos pesquisando e redigindo a dissertação. E eu já estava fazendo uma coisa pela qual me apaixonara, então fiz o mestrado trabalhando no Arquivo.

Revista Epígrafe: E, Silvana, ainda nesse começo da sua experiência profissional, além do Arquivo do Estado, você chegou a trabalhar em alguma outra instituição?

Silvana Goulart: Eu dei aula no $3^{\circ}$ grau, de História do Brasil República, por um tempo, em uma Faculdade particular de Ciências Sociais, a Escola Pinheirense, que hoje não existe mais. E na Escola de Sociologia e Política também por um ano. E eu estava nessa dúvida de saber se queria fazer carreira acadêmica. O meu orientador, já falecido, o Witter, fazia uma certa pressão para que eu o seguisse. Eu gostava muito dele, tinha trabalhado com a mulher dele, uma grande psicóloga, uma pesquisadora incrível - a Geraldina Porto Witter. Eles foram um pouco meus pais, além de amigos, porque eu tinha vindo há pouco para São Paulo e precisava muito daquele apoio. Mas eu segui a carreira que ele me apontou, via Arquivo do Estado. 


\section{entrevista|}

Silvana Goulart

Revista Epígrafe: E, pensando que você iniciou de maneira mais prática, na arquivologia, você acha que o curso de História que tinha feito de alguma forma te preparou para trabalhar nessas instituições, e se tinham, talvez, algumas disciplinas já naquela época que te ajudaram para isso?

Silvana Goulart: Olha, no curso de História, essa perspectiva era bem distante. Eu tive duas experiências com documentação antes de trabalhar no Arquivo do Estado. A professora, hoje aposentada, [Maria] Thereza Petrone, que trabalhava com a produção de café em São Paulo, orientou um trabalho no Arquivo do Estado, onde cada grupo de alunos escolheu uma região cafeeira e analisou documentos. O meu grupo pesquisou a região de Santa Branca, mas foi uma experiência preliminar, sem muita amarração. O meu orientador, José Sebastião Witter que trabalhava com História do Brasil República, coordenou também uma pesquisa com revistas semanais dos anos 1920, também no Arquivo do Estado. Me lembro de Thereza Petrone dizer aos alunos que não esperassem que alguém os tomasse pela mão para que fossem historiadores - creio que ela tentava nos alertar para que tivéssemos uma postura mais proativa para definir e perseguir um rumo profissional. Na UFMG os alunos frequentavam mais regularmente o Arquivo Público Mineiro, mas não dá para saber se isso resultava em um preparo maior para lidar com documentos históricos. Mas resumindo, creio que a formação do curso de História da USP na época em que estudei, não tinha uma perspectiva formadora quanto a pesquisa e os documentos de onde tiraríamos os insumos para fazer história.

Revista Epígrafe: Sim, mas hoje temos a disciplina da professora Ana Maria Camargo. 


\section{entrevista}

Uma vida entre História, memória e arquivo

Silvana Goulart: Exato, a Ana Camargo foi entrando por esse viés pois já havia feito o doutorado sobre a Hemeroteca Júlio de Mesquita, fazia pesquisa sobre a Imprensa Régia e era uma colecionadora de livros, uma bibliófila. Ela se interessava muito por tudo isso, depois teve a experiência no Arquivo do Estado e foi mergulhando na Arquivística.

Revista Epígrafe: E depois do seu ingresso na área de arquivos você se especializou de alguma maneira em arquivologia?

Silvana Goulart: Eu passei a estudar, me aproximei do CPDOC [Centro de Pesquisa e Documentação de História Contemporânea do Brasil, da Fundação Getúlio Vargas], que reunia arquivos pessoais da elite política brasileira a partir dos anos 1930. Trabalhei com a metodologia produzida ali para fazer o Inventário do Júlio Prestes. Essa instituição, criada nos anos 1970, estava se tornando uma referência na área.

Revista Epígrafe: Silvana, a gente queria mudar um pouco de assunto agora. Você podia contar para a gente como foi a fundação da Grifo? Essa guinada de alguém que trabalhava em arquivo para uma empresa, como é que foi isso?

Silvana Goulart: No Arquivo do Estado, o convênio com a Imprensa Oficial do Estado estava se esvaziando, o que era preocupante. Fiquei sabendo que a historiadora Zuleika Alvim, fundadora da Grifo, que trabalhava com o arquivo do Mappin, estava procurando pesquisador e me candidatei. Ela tinha feito um livro sobre a história do Mappin, uma das primeiras lojas de departamento de São Paulo, um livro pioneiro sobre história do comércio e de uma casa comercial, o que nunca tinha sido objeto da historiografia entre nós. O livro teve uma ótima repercussão, inclusive na imprensa, 


\section{entrevista|}

Silvana Goulart

pois o estabelecimento era uma referência na cidade, e ela conseguiu convencer a diretoria do Mappin a cuidar do arquivo da área de marketing, com 60 mil recortes de jornal, que na verdade eram reunidos apenas para comprovar que os anúncios contratados haviam sido publicados na imprensa e portanto podiam ser pagos. Essa casa comercial, de origem inglesa, o Mappin Stores, que inicialmente vendia louças, pratarias e adornos para casa havia se transformado com o tempo em uma loja de departamentos. No início era um estabelecimento de elite, mas a partir da Segunda Guerra Mundial e a interrupção de abastecimento estrangeiro passou a vender produtos da indústria brasileira. Antes até os tecidos vinham de fora e o Mappin tinha costureiras, alfaiates, chapeleiras, camiseiros para fazer roupas finas e vendia móveis produzidos pelo Liceu de Artes e Ofícios. E depois, com a carência das importações, começou a vender todo o tipo de produtos industriais brasileiros, eletrodomésticos, roupas, artigos esportivos, colchões, enxoval de casa, enfeites etc. E esse arquivo de 60 mil recortes contava a história da cultura material desde a fundação do Mappin, em 1913, até os anos 1990, testemunhando a época do requinte com seus catálogos de moda feminina, masculina e infantil, listas de enxoval e anúncios de roupas para a temporada de ópera em São Paulo para o carnaval, para a prática de esportes, etc. Foi uma das primeiras lojas de departamento de São Paulo, com salão de chá, desfiles de moda e vitrines. O arquivo vinha sendo organizado pela Zuleika Alvim em uma casa no Itaim Bibi quando entrei na Grifo. Uma equipe contratada tratava da conservação do acervo, descolando os anúncios dos álbuns e descrevendo em fichas manuais, como se fazia na época. Como eu tinha experiência com arquivo histórico, comecei a coordenar os trabalhos. O arquivo do Mappin se tornou uma referência em São Paulo. Depois nos mudamos para um andar de um prédio da rua Xavier de Toledo, no centro, próximo à loja matriz, em uma das esquinas mais famosas da cidade, em frente ao Teatro Municipal. Lá continuamos a tratar do arquivo e a receber 


\section{entrevista}

Uma vida entre História, memória e arquivo

pesquisadores de história da cidade, do comércio, de desenho publicitário, linguagem de anúncios, imigração italiana, confecção de roupas, etc. Então eu fiquei com um pé no arquivo e outro na pesquisa, porque nesse meio tempo, a Grifo começou a fazer uma pesquisa sobre a história da Escola Politécnica da USP, que completava seu centenário. Fizemos um livro, uma exposição e viabilizamos duas esculturas públicas para o campus da Escola, na Cidade Universitária, dos artistas Denise Milan e José Resende. E começamos a trabalhar também com o arquivo histórico da Companhia do Metropolitano de São Paulo, o Metrô - um arquivo maravilhoso de imagens sobre a cidade antes e depois dos trens subterrâneos. Esses novos trabalhos nos levaram a outras possibilidades para além da academia e um mundo amplo se abriu para nós.

Eu me tornei sócia da Zuleika, no fim dos anos 1980, morrendo de medo. A academia e todos os meus amigos tinham uma certa rejeição e eu entendia muito pouco do mundo onde estava entrando. E fazer história institucional também é complicado, pois há limites para se falar do negócio. Apesar das pesquisas primorosas que realizávamos, havia um limite para enfrentar as contradições. Vou dar um exemplo: o prédio do Mappin foi um dos primeiros art-déco da cidade, construído pelo arquiteto Elisiário Bahiana, responsável também pelo Viaduto do Chá. Era um prédio de linhas retas, emblemático, um marco da cidade e ficava do lado novo, para onde vinha o comércio, do outro lado do Viaduto. A loja sofreu um incêndio que não podia ser mencionado, pois evidenciava o risco de que, se isso ocorresse, não houvesse a segurança necessária para evacuar o prédio.

Mas entrar na sociedade da Grifo foi também uma alegria, pois apesar do risco, há uma grande liberdade de inventar e concretizar ideias, contanto que se convença alguém a pagar para ver. 


\section{entrevista}

Silvana Goulart

Revista Epígrafe: Silvana, aproveitando isso que você falou, poderia dizer para a gente nesse começo, pode ser até hoje, quais são os desafios de um de um historiador que vai trabalhar em uma empresa? Você falou do pessoal da academia que não entende muito bem esse lado, mas quais são os desafios para alguém que sai da academia e vai ser empresário?

Silvana Goulart: O problema inicial é que não se tem formação para a função. No caso da Grifo, fizemos muitos "cursos de madureza" sobre temas que não dominávamos, por meio da contratação de consultores, conversas com amigos empresários. Não é uma coisa fácil. No caso da Grifo, pegamos um tempo de hiperinflação, o que colocava problemas sérios para orçar os trabalhos e levá-los até o fim sem que ficassem financeiramente inviáveis. Foi muito difícil, mas tivemos sempre muita sorte, nunca ninguém se aproveitou da nossa da inocência em lidar com essas questões. Outra coisa que ajudou foi que tratávamos sempre com as esferas mais altas da empresa e nos beneficiamos com a postura ética das pessoas. Foi um negócio louco pela inexperiência inicial - na verdade éramos um grupo de amigas que convidava outros amigos para desenvolver projetos junto com a gente.

Revista Epígrafe: Só para a gente se situar: de que período é a fundação da Grifo? E a sua entrada?

Silvana Goulart. Entrei na Grifo em 1988. A microempresa já existia com a Zuleika e outra sócia desde 1986. Quando eu cheguei, o livro do Mappin estava editado com muita qualidade, coisa não comum nos livros acadêmicos, e tinha recebido críticas muito positivas nos melhores jornais e revistas, pois era inédita uma história sobre uma loja que todo mundo conhecia, a trajetória do comércio paulistano e do centro 


\section{entrevista}

Uma vida entre História, memória e arquivo da cidade, o famoso salão de chá do Mappin, sala de visitas da elite e palco de exposições de artistas, como Anita Malfatti. Quanto à Grifo, havia grande animação para continuar a trabalhar com história, mas a dificuldade do negócio era explicar às pessoas o que a gente fazia - "Como assim, vocês querem contar a nossa história?".

No começo dos anos 1990, houve um fato importante: a Grifo foi convidada a fazer uma pesquisa sobre a cidade de Poços de Caldas para o que viria a ser o Instituto Moreira Salles. O embaixador Walter Moreira Salles montou uma Casa da Cultura, o embrião de um empreendimento que ele faria em vários pontos do Brasil, pois sua casa bancária começara naquela cidade de águas termais, infraestrutura hoteleira e cassinos. Foi um ponto de inflexão para a Grifo, pois fomos trabalhar com um grupo que compreendia e valorizava o nosso trabalho. Fizemos pesquisa sobre a cidade que foi por décadas um ponto de encontro da elite que ia tratar da saúde e veranear - Poços foi um centro de lazer da elite brasileira. Colhemos depoimentos de várias pessoas da cidade, inclusive sobre os cassinos, fizemos pesquisa sobre João do Rio, cronista carioca que escreveu um livro epistolar sobre Poços de Caldas, e sobre o início da imprensa mineira para as exposições de abertura da Casa da Cultura.

Enfim, voltando à questão da Grifo, creio que há muitos problemas para quem não acompanha de perto a legislação, a burocracia fiscal, entre outras coisas. Mas a gente entra sem saber tudo o que pode dar errado e eu acho que, às vezes, uma certa inocência ajuda você a começar.

Revista Epígrafe: A gente gostaria de saber, uma vez que a Grifo é uma referência na área de projetos culturais no Brasil, como você descreveria o trabalho atual da empresa, o modo como vocês trabalham? 


\section{entrevista|}

Silvana Goulart

Silvana Goulart: A Grifo passou por muitos momentos difíceis em que nada acontecia e em uma época, fechamos um escritório que tínhamos na rua João Moura para cortar despesas. Na época, já tínhamos outra sócia, a Lygia Rodrigues, também historiadora e mestre em Ciências Sociais e com pós-graduação em Arquivologia. Aos poucos, fomos retomando os trabalhos. A Zuleika Alvim era muito conhecida por um livro que escrevera sobre a imigração italiana no Brasil - Brava Gente! - fruto da sua dissertação de mestrado, que fez muito sucesso, mesmo fora da universidade. As nossas especializações se complementavam e aos poucos fomos retomando. Enfrentamos concorrências públicas e privadas, perdemos muitas, mas também ganhamos trabalhos interessantes. Começamos a trabalhar também com organizações não governamentais. E ao lado da vertente de trabalho com acervos históricos, desenvolvemos muitos projetos editoriais e culturais. Escrevemos vários livros institucionais e temáticos, com pesquisas inéditas. Passamos a fazer avaliações, dar consultorias, tivemos experiência com curso à distância. Fizemos exposições que comumente acompanham o lançamento de livros ou divulgam documentos históricos dos centros de memória. Desde os anos 2000, o mercado é diferente, é muito mais fácil se falar de memória e não é preciso explicar do que se trata, todo mundo sabe, tem uma referência de prestadores de serviço, de trabalhos feitos para empresas ou instituições. Então se pode dizer que é uma atividade reconhecida.

O difícil é a compreensão de que trabalhar com a memória requer um investimento mais ambicioso das empresas, sobretudo se o objetivo é entender o negócio, a cultura da organização, a fim de pensar o presente e tomar decisões. Estamos no meio do caminho: se sabe que visitar o passado é interessante, mas muitas vezes esse passado é restrito apenas à gênese do empreendimento. Todo mundo quer falar daquele começo heroico, e esse de fato é um tempo importante da formação de uma identidade e de uma cultura. Quando a organização é antiga, ela 


\section{entrevista}

Uma vida entre História, memória e arquivo quer realçar sua tradição, o que é uma maneira de se diferenciar. Mas ainda não se avançou efetivamente para um patamar no qual a empresa possa usar o conhecimento de sua trajetória para lidar com o presente. Trabalhar a memória com essa ambição requer equipes interdisciplinares, uso de tecnologia e sobretudo, proximidade com a organização para compreender suas demandas.

Conseguimos, com muita dificuldade, reunir um grupo de empresas em uma associação, a Associação Brasileira de Memória Empresarial (ABME). Por seis anos, vários centros de memórias de grandes empresas se juntaram para tentar formar uma rede e, nesse caminho, alguns deles foram desativados e outras organizações desistiram. Até com a operação "Lava Jato” houve desativação de centros de memória. Mas algumas persistiram e conseguiu-se criar uma associação para promover formação, troca de informações para demonstrar que a memória é um investimento interessante. A ABME foi fundada com a Fundação Bunge, a Votorantim, o Grupo Globo, a Klabin, a Grifo e a Tempo \& Memória, essas duas últimas prestadoras de serviço pioneiras nessa área. Hoje estamos tentando agregar novas organizações - já conseguimos a Memória da Eletricidade - e sabemos que essa mudança de paradigma dos centros de memória vai acontecer e a união é um fator essencial. Hoje partimos da premissa de que a memória institucional deve ter o presente como ponto de partida - os desafios de hoje seriam uma chave para olhar o passado e, também, é de lei não perder as mudanças que a organização está vivendo hoje, em um mundo cada vez mais rápido e dinâmico. É preciso convencer as pessoas que a história não está presa em um passado remoto, mas está sendo engendrada agora o que não é fácil -, e de que arquivo é fonte de informação fidedigna, pois existe para registrar as ações e viabilizá-las. Mas há preconceitos muito arraigados. É uma missão um pouco quixotesca, mas sempre interessa aos mais neuróticos, grupo no qual me incluo. 
Silvana Goulart

Revista Epígrafe: Silvana, você poderia pensar um pouco com a gente como é a gestão de projetos culturais no Brasil? Quais são as especificidades de trabalhar com isso hoje aqui no Brasil?

Silvana Goulart: Hoje, nesse momento, é trágico, pois estamos vivendo um governo que trabalha para restringir isso. É uma atividade que precisa de uma formação e hoje temos cursos para produtores culturais, no SESC [Serviço Social do Comércio], na Fundação Getúlio Vargas, mas sinto que ainda são um pouco genéricos. Conforme a minha experiência na Grifo, acho que a formação deveria ser mais efetiva, ensinando a gerir uma empresa, no caso de se querer empreender na cultura por meio de um escritório próprio. Outro ponto necessário é aprender a gestão de projetos de incentivo cultural, por meio de leis municipais, estaduais e a federal. Essas leis hoje são importantes para o financiamento da cultura e não é fácil cumprir todas as suas exigências passando pela aprovação do projeto, financiamento, prestação de contas. O mais difícil, na verdade, é captar recursos para realizar os projetos. Existem escritórios especializados nisso, mas temos que considerar que é um gargalo, já que apenas $20 \%$ dos projetos aprovados na Secretaria da Cultura (antigo Ministério da Cultura, o MinC) conseguem patrocínio.

A Grifo, hoje, tem muito interesse em aprofundar a atuação cultural, pois muitas vezes eles coincidem com nossos projetos pessoais. Se eu tenho vontade de trabalhar com arte contemporânea, por exemplo, posso fazer um projeto cultural e tentar interessar uma empresa a investir naquilo. Com a entrada de uma nova sócia, a Thaís Gurgel, jornalista com formação na ECA e mestrado em Educação na área de Linguagens da Arte, essa tendência se fortaleceu. Queremos trabalhar com memória institucional, centros de memória e produção cultural e essas vertentes se 


\section{entrevista}

Uma vida entre História, memória e arquivo aproximam, pois, atualmente, é exigido que o trabalho com documentação resulte em difusão e os projetos culturais surgem daí. O tempo todo a demanda é compartilhar com a instituição e com a sociedade as informações que surgem da pesquisa dos documentos históricos. Hoje, a nossa preocupação, no sentido da produção cultural, é perceber como as informações podem ser de interesse das pessoas, se coincidem com o que estão buscando para direcionar as suas vidas. As novas gerações trazem novas ambições - talvez a prioridade do carro seja menor em relação à qualidade de vida. As pessoas estão mais abertas a compartilhar e almejam outros futuros e não acredito que sem utopia. Certamente não ignoro que há uma parcela do mundo que é puro pragmatismo, mas há outra que procura a cultura e a arte, e esta vislumbra outras possibilidades. Se não, pelo amor de Deus, nós vamos morrer de realidade.

Revista Epígrafe: Você desenvolveu dois importantes trabalhos com a professora Ana Maria Camargo no campo de arquivologia. Poderia falar um pouco dos livros relacionando com seu trabalho no campo da gestão cultural e como foi esse processo?

Silvana Goulart: O livro Tempo e circunstância nasceu na Fundação Fernando Henrique Cardoso como fruto da construção de metodologia para tratar arquivos pessoais. Mas ele aponta para um método de trabalho com qualquer arquivo, pois propõe uma maneira de aplicar a descrição contextualizada dos documentos. O livro faz, inicialmente, a defesa da importância dos arquivos pessoais, não considerados pela ala mais tradicional da arquivologia, e defende um método científico para tratálos, a partir do entendimento do contexto da produção dos papéis, apesar da subjetividade e da informalidade de uma parte dos documentos pessoais. E esses 


\section{entrevista}

Silvana Goulart

caminhos são demonstrados pela discussão de conceitos, pela apresentação em detalhe da descrição documental e de um modelo de base de dados que dá conta de responder às pesquisas feitas no acervo. Acho que foi uma grande oportunidade podermos realizar um livro técnico, bilíngue e bem editado. A Fundação FHC nos deu a possibilidade de trabalhar na construção de um método e de divulgá-lo, certamente por ser uma instituição com viés acadêmico, que vê sentido na pesquisa e na ciência. O acervo de Fernando Henrique Cardoso também deu visibilidade ao trabalho, pois é talvez o único arquivo presidencial que está sendo organizado e colocado à disposição do público via internet, além de ser sistematicamente divulgado por exposições presenciais e virtuais, visitas técnicas e presença nas redes sociais. A credibilidade que a instituição ganhou com a sua atuação é importante para corroborar o trabalho com seus acervos, pois além do de FHC, a Fundação custodia os de Ruth Cardoso, Joaquim Ignácio Cardoso, Leônidas Cardoso e de Paulo Renato Souza e Sérgio Motta (ambos ministros do governo FHC). O livro Tempo e Circunstância deveria ser revisto hoje pois acréscimos e correções foram feitos, já que a metodologia continua em construção.

Revista Epígrafe: O seu livro sobre centros de memórias veio do trabalho com as empresas, mas foi feito junto com Ana Maria Camargo, porque ela também fez muito desse trabalho.

Silvana Goulart: Eu comecei a chamar a Ana Maria para discutir os centros de memória, pois ela é uma mulher de arquivo, conhece o pessoal e havia vivido a experiência no Arquivo do Estado, além de ter sido por anos diretora do Arquivo Municipal de Rio Claro. O centro de memória é um outro mundo, o lugar onde muitas vezes se recolhe o que sobrou dos arquivos das organizações, mas não pode 


\section{entrevista}

Uma vida entre História, memória e arquivo

prescindir deles. É uma encrenca. E como convencer as organizações a representar todas as suas atividades por meio dos documentos que produziu para cumpri-las? É uma coisa muito complexa promover um entendimento com as organizações cuja visão de memória é, muitas vezes, restrita. Mas houve um processo. Eu convidei a Ana Maria para fazer junto uma consultoria no Sesc São Paulo, com a equipe responsável pela criação do Sesc Memórias. Foi um ano de muita reflexão e ao final ela já estava fascinada pelo tema. O Sesc é uma instituição aberta e possibilitou que se discutisse e amadurecesse a ideia do seu centro de memória dando a ele uma versão plural, pois sem dúvida as memórias são várias e se sobrepõem. O contraponto com a Ana Maria é ótimo, pois temos experiências diferentes e perspectivas nem sempre iguais, o que enriquece o trabalho.

Sou muito orgulhosa desse livro, Centros de memória: uma proposta de definição. Ele discute alguns limites que devem ser ultrapassados, pois hoje existe um discurso que não se efetiva na realidade. Se diz que o centro de memória é estratégico para a empresa, que pode trazer soluções, o que ainda não ocorre, e o livro busca identificar o que falta, quais as pontas que se devem juntar. $\mathrm{O}$ mundo mudou, então falar de arquivos como antes não faz muito sentido. É preciso inventar outras maneiras de trabalhar a informação e fazer dela um corpo de conhecimento inteligível.

Os centros de memória são arquivos ampliados, pois guardam documentos úteis para sua operação, também colhidos fora da instituição. E pensando no uso acadêmico desses acervos, se constata que o pesquisador não tem como fazer história econômica, por exemplo, só em arquivos públicos, isso não existe. É preciso consultar os acervos das empresas privadas. 


\section{entrevista|}

Silvana Goulart

Revista Epígrafe: Antes da gente passar para nossa fase final, pensando nos cursos de gestão na FGV, SESC, Itaú Cultural, a senhora acha que os cursos de História deveriam tentar também abarcar essa ideia da gestão cultural? A gente pensar em algumas mudanças na grade curricular para abarcar essas novas atuações do historiador...

Silvana Goulart: Seria interessante demais que houvesse opções para estudar a gestão de projetos. Para outros tipos de disciplina, creio que haveria resistências a enfrentar. Há algum tempo, uma professora do Departamento de História, acho que a Marlene Suano, tentou propor um curso sobre história institucional e houve uma rejeição. Então, eu não sei até que ponto o Departamento de História teria uma cultura para abranger uma perspectiva profissional a fim de completar a formação dos alunos. Quando estudei, nos anos 1970, até os temas de pesquisa tinham uma avaliação politicamente correta e vicejavam as pesquisas sobre o movimento operário - dá para entender, estávamos saindo da Ditadura. Mas hoje se tem uma historiografia ampla, que inclui mentalidades, cotidiano, minorias, etc. Mesmo em relação a trabalhos com acervo existe preconceito. Por exemplo, dentre as várias pessoas que estagiaram na Fundação FHC, vindas do Departamento de História, algumas não comentavam que trabalhavam lá, pois um arquivo de um político considerado liberal só pode ser liberal... Tudo isso mostra a falta de entendimento em relação aos arquivos e a operação que fazem os documentalistas. A função do arquivista é colocar as fontes à disposição de quem for trabalhar com o acervo e usar o método científico para torná-las inteligíveis. O trabalho do historiador é outro e é incrível que as pessoas não façam a diferença.

Revista Epígrafe: Quais competências você acha essenciais para um documentalista, historiador, empresário? 


\section{entrevista}

Uma vida entre História, memória e arquivo

Silvana Goulart: O documentalista precisa ter vocação, pois a atividade requer paciência e precisão, pesquisa sobre o acervo, de contexto de época, pesquisa de vocabulário, rigor com o uso das palavras, uniformidade na descrição. É o reino da filigrana e do rigor. Mas existe a ideia pré-concebida de que quem trabalha com documentação fica sempre fazendo a mesma ficha, o que é de uma ignorância absurda. Quando o documentalista é historiador, ele compreende melhor os vários usos dos documentos, seu peso e importância para a construção de uma narrativa histórica.

O historiador vai usar esse material para comprovar hipóteses que ele constrói estudando um período, lendo a literatura existente e formulando questões sobre como ocorreram as coisas, por que e com que desdobramentos. Ele vai analisar as fontes, atribuir a cada uma o seu peso e examiná-las com um olhar crítico quanto à fidedignidade e possibilidade de comprovar o que ele deseja, vai explicitar as premissas teóricas de onde fala e fazer uma narrativa alicerçada nessas fontes. Ele pode ser mais ou menos crítico, de acordo com as premissas de onde parte.

Os trabalhos de historiadores e documentalistas são interdependentes, pois se as fontes não foram contextualizadas, serão entendidas de forma errônea. Isso pode acontecer também se o historiador não conhecer as estruturas sociais e políticas do tempo que está investigando, o ordenamento jurídico desse tempo, o funcionamento das instituições. Ou seja, para tudo é preciso compreender o contexto. Nada impede que se trabalhem fontes como documentalista e também como historiador - esse seria o melhor dos mundos pois a intimidade com os documentos ajuda a fazer uma análise correta. 


\section{entrevista|}

Silvana Goulart

Revista Epígrafe: Silvana, pensando no seu lado de empresária, quais seriam as competências do um historiador/historiadora que se torna empresário?

Silvana Goulart: O historiador que quer empresariar deveria se aparelhar sobre o que não conhece. Hoje há muitos cursos, MBAs [Master in Business Administration], especialização de várias matérias - administração, controle de finanças, gestão de projetos, comunicação, vendas, tecnologia etc., e não precisa sofrer tanto como ocorreu conosco na Grifo. Mas mesmo com menos recursos - a Grifo existe há mais de 30 anos - contratamos consultorias com pessoas competentes que nos orientaram. Mas se as pessoas estiverem mais aparelhadas, melhor, pois o mundo está mais complexo. Há empresas que têm sócios com formação em Administração, por exemplo, que sabem organizar o fluxo de trabalho, a parte financeira, de pessoal etc., mas sempre vai se precisar de assistência contábil e jurídica, pois há um cipoal de impostos e leis a respeitar. Havia nos anos 1980, poucos escritórios no mercado hoje não daria para perder tanto tempo como foi o nosso caso, tentando se virar para tocar o negócio. É isso, eu acho que a inocência não ajuda ninguém. E não há como entender de tudo, por isso é preciso ter bons parceiros.

Revista Epígrafe: Trabalhar com arquivo fez a senhora repensar sua atuação como historiadora? Ou mesmo repensar aquela graduação em História que fez?

Silvana Goulart: É, boa pergunta, viu? [risos] Eu acho que a história sempre foi a base de tudo. Por todas as vias - organização de documentos permanentes, projetos culturais, centros de memória - a História é o ponto de partida e de chegada. Eu gostaria de ter mais tempo para ser historiadora, para trabalhar um tema que conheço como documentalista. Mas não dá tempo, é muita demanda e em um 


\section{entrevista}

Uma vida entre História, memória e arquivo escritório tem muitas coisas gerenciais para fazer, além de vender projetos, organizar o trabalho e coordenar pessoas. Todo mundo é meio multiuso. E assumir um escritório significa que você tem pessoas sob a sua responsabilidade. Quando começou a pandemia, ficamos preocupadas em saber se as pessoas estavam liberadas para trabalhar em casa, se estavam correndo riscos etc. Felizmente as empresas liberaram as pessoas para o home office e acabou todo mundo entrando em quarentena.

Revista Epígrafe: Bom, Silvana, a gente está indo para o nosso final aqui. Que dicas você daria para um estudante de História que quer entrar nessas áreas? Seja como documentalista, seja criando uma empresa, sendo empresário na gestão cultural.

Silvana Goulart: Eu acho que o pessoal que está na graduação deveria fazer estágios em atividades diferentes, para entender o que gosta, o mercado, as possibilidades. Pessoas que já trabalharam conosco hoje trabalham com arquivos, com programação cultural, em museus, como curadores, em empresas de exposição, como pesquisadores autônomos, mesclando isso com docência e pós-graduação. Elas conciliam as coisas, o que é muito propício para o mercado de hoje que precisa de um profissional multifacetado. Eu acho interessante esse modelo, pois uma coisa complementa a outra. Mas voltando ao trabalho com memória, felizmente ele hoje tem muita visibilidade e a intuição me diz que a pandemia vai ampliar essas possibilidades. No meu caso, foi muito trabalho para me fazer entender como trabalhadora da memória, mas também me diverti correndo atrás de uma perspectiva que no início era quase uma utopia. 